\title{
Teaching Reform and Innovation in Architectural Design Based on the "Internet +"
}

\author{
Fang Wang \\ School of Urban Construction \\ Wuhan University of Science and Technology \\ Wuhan, 430000, China
}

\begin{abstract}
With the development of "Internet +", the traditional construction industry, relying on Internet technology, has achieved the connection between the network and the industry. The development of "Internet + " has brought about a new round of revolution in informatization and visualization, and has also promoted the reform and innovation of traditional architectural design teaching. Based on the author's learning and teaching experience, this work first analyzed the opportunities and challenges that "Internet + " brings to the teaching reform in architectural design, and then put forward feasible countermeasures for teaching reform and innovation in architectural design guided by "Internet +". It includes creating teaching scenarios, determining work contents, making implementation plans and selecting working methods.
\end{abstract}

Keywords-"Internet +"; Architectural Design; Situational Teaching; Teaching Reform

\section{INTRODUCTION}

Facing the current industrial reform, the pace of teaching reform in colleges should also follow closely, responding to the current hot technology updates in the industry. As a major closely related to social environment and economy, architectural design should actively respond to the needs and problems of the industry. Based on the concept of "Internet +", the architectural design course not only uses computer as a simple demonstration tool, but also combines the network technology with the course teaching organically. The Internet will be used as a new platform to update the teaching system, change teaching methods and link social resources. The core of architectural design course needs to clarify the relationship between "Internet $+"$ and urban demand, environmental demand, architectural demand and crowd demand, so as to make the teaching theme more directional. The course is different from the traditional teaching method of "one grass, two grass", which is based on the design plan with the program and the drawing control of the teaching depth. The architectural design teaching guided by "Internet + " helps students to think about problems from different professional perspectives. Students can start from the purely finished curriculum design drawings and start from the needs of the venues, so as to solve the problems in the curriculum.

\section{The OpPortunity AND Challenge OF "INTERNET" TO THE TEACHING REFORM IN ARCHITECTURAL DESIGN}

From the perspective of teaching methods, various universities have introduced the software and hardware equipment in classroom multimedia teaching since the 21 st century. Teachers will also make multimedia courseware before teaching, and add some pictures, videos, etc., to increase the richness and interest of teaching, which really changes the traditional teaching method of "textbook + blackboard". However, teachers are still the main body of the classroom, and pay more attention to knowledge teaching. Rich PPT no longer has a strong attraction, and students can't help but brush their mobile phones for extended search due to a small problem. In addition, some theoretical courses are relatively abstract and difficult for students to understand. Even though teachers use relatively simple multimedia courseware to assist related pictures and short videos to enhance students' understanding of related concepts, the class time is limited. The concepts are more and difficult to understand, and it is difficult to achieve ideal teaching only by teachers' explanation and interaction between teachers and students in the class. Students are often busy taking PPT or recording the teacher's explanation with their mobile phones, which affects the effect of classroom acceptance.

Some reports show that college students have a high degree of dependence on the Internet. The online time is significantly longer than the past history. $62.5 \%$ of college students spend more than 5 hours online every day, and $25 \%$ of college students spend 3-5 hours online every day. In the Internet era, mobile phones are becoming more and more rich in functions, and various kinds of software are emerging in an endless stream. Businesses are also trying their best to attract the attention of young people. Social networks, mobile games, video software and shopping apps are also full of variety in an independent university. Students' attention is often attracted by the novel Internet. Similarly, in the classroom teaching, students will also present a new acceptance psychology (i.e., they think that the teacher's knowledge can be supplemented by their own reading materials or other reference books after class), so they are distracted in the classroom. It is difficult to read in time after class, and it is unable to preview independently before class, which results in the phenomenon that learning is not systematic, and basic knowledge learning is weak and analysis ability is insufficient. Once related homework is arranged for discussion, students are also very dependent on the Internet, and online search is the main way to find information. Therefore, in the "Internet +" era dominated by information technology, the realistic problem we must consider is to readjust the teaching ideas, and stimulate students' interest in reading and thinking. At the same time, we 
must also take advantage of the Internet to satisfy students' curiosity and stimulate their thirst for knowledge, so as to enliven the classroom atmosphere and achieve the purpose of teaching.

The advent of the Internet age has broken the barriers between space and time, and provided the foundation for the advancement of new teaching methods. In recent years, with a whole set of information technologies advances such as mobile Internet, cloud computing, big data, etc., "Internet +" has also become a hot topic. In 2015, the Guidance from the State Council on Actively Promoting the "Internet +" Action were issued. Regarding education, it puts forward the opinion on "exploring new supply mode of education services". It is necessary to encourage Internet enterprises and social education institutions to develop digital education resources, and provide network education services according to market demand. Schools are encouraged to use digital education resources and education service platforms, gradually explore new models of network education, expand the coverage of high-quality education resources, and promote education equity. Schools are encouraged to connect online and offline education resources, and explore new ways to provide basic education, vocational education, etc., through cooperation with Internet enterprises. This will promote the sharing of online curriculum resources for academic education, and promote online learning models such as large-scale online open courses. The establishment of credit recognition and credit conversion systems for online learning are explored, and the reform of higher education service model are accelerated. "Online courses" and "online learning mode" have indeed changed the thinking and concept of traditional classroom teaching. Profound changes have taken place in teaching design, teaching methods, teaching objectives, teaching platform and the mode of discussion between teachers and students. From primary and secondary schools to universities, they are consciously relying on the Internet to carry out teaching mode reform. There are many new teaching exploration methods, such as MOOC class, micro class, flipped class, etc. At the same time, each school is also trying to build a platform for sharing teaching resources, increasing the diversity of knowledge dissemination and acceptance, so as to promote the diversity of students' choice.

\section{The Feasible Path of Teaching Reform And INNOVATION IN ARCHITECTURAL DESIGN GUIDED BY "INTERNET"}

\section{A. Creating teaching scenarios}

Multi-dimensional teaching resources. In general, the content of teaching is composed of degradable and interactive teaching contents based on the "Internet +", which combines theory with practice and enriches the content of courses. It can effectively improve teaching efficiency and achieve teaching objectives. The emergence of the Internet offers rich resources and materials for teachers' teaching content, and high-quality online courses offer a good reference for teachers to design curriculum content. With the continuous development of Internet technology and information technology, all kinds of learning resources can be connected and used in the form of hypertext and hypermedia. It will not be limited by region and discipline, and realizes barrier free docking between virtual and reality. In order to fundamentally change the traditional teaching mode, it is necessary to pay attention to the teaching resources related to students' inquiry-based learning and collaborative investigative learning in the development of the course content, and shift from the traditional teacher-oriented teaching to both teaching and learning.

Making multimedia courseware and expanding information content. Multimedia courseware mainly uses multimedia tools such as words, pictures, videos, etc., to design teaching contents according to teaching syllabus and teaching purpose. Students majoring in art design in universities focus on intuition, imagination and comprehensive functions in their thinking mode. The multimedia courseware can meet the visual sense requirements of the students majoring in art and design. It can make full use of the teaching media to create an intuitive classroom scene and make the teaching content more intuitive and visualized. It is more in line with the thinking characteristics of students majoring in art and design, which is helpful for students' understanding and memory.

Teaching activity planning. First of all, teachers should create new and interesting problem situations to guide students' attention, and pay attention to the guidance and materials between students. They should encourage students to make full use of the learning resources on the Internet platform, and establish their own knowledge system, so as to stimulate students' interest in learning. Secondly, according to the differences of students' individual learning ability, learning level and learning preferences, the students are grouped by teachers scientifically, so that the students can cooperate, discuss and communicate in the group. Finally, the interaction between teachers and students, students and students is emphasized in the scene design. For example, the online forum, QQ group, WeChat group, network sand table, etc., are used to interact with each other to improve the learning process.

Using virtual technology. Students majoring in art design can make full use of virtual technology to create learning environment, so as to achieve their own learning objectives. For example, students majoring in art and design can use audio and video transmission, data collaboration and other transmission technologies to simulate the real classroom environment, and obtain effective teaching scenarios through the Internet platform.

\section{B. Determining work contents}

The optimization and integration of architectural design curriculum resources mainly three aspects, including the learning and practice of "Internet +" knowledge and skills, the optimization and integration of professional curriculum resources, and the construction of professional resources platform (as shown in Fig. 1).

The learning and practice of "Internet + " knowledge and skills. It is necessary to strengthen the training for "Internet +" and other new generation of educational information theory and technology, improve teachers' educational technology ability, and promote the development of teachers' information. By holding "Internet +" theme forums and lectures, students' information literacy and learning ability are improved, and a 
The construction of professional resources platform. Based on the "Internet +" new generation of information technology, the relevant knowledge resources such as syllabus, electronic courseware, question library, review navigation, teaching video, enterprise case, etc., will be designed for the major courses of construction. Professional resource repositories and curriculum websites should be constructed. Online answering and interactive links should be set up, which helps to teach and learn online and offline, and realize the network modernization of professional education and teaching. Unlike the previous excellent course website, the "Internet +" platform has the advantages of new technology, institutional advantages and wider social support, especially in the application of 5G and Wi-Fi technology based mobile Internet. It really achieves personalized learning, customized learning and learning anywhere (as shown in Fig. 2). employment information, the resource content of each maj course is set up, and the resource standard of each major course is reformulated, so as to offer democratic, relaxed and harmonious teaching atmosphere for teachers and students.

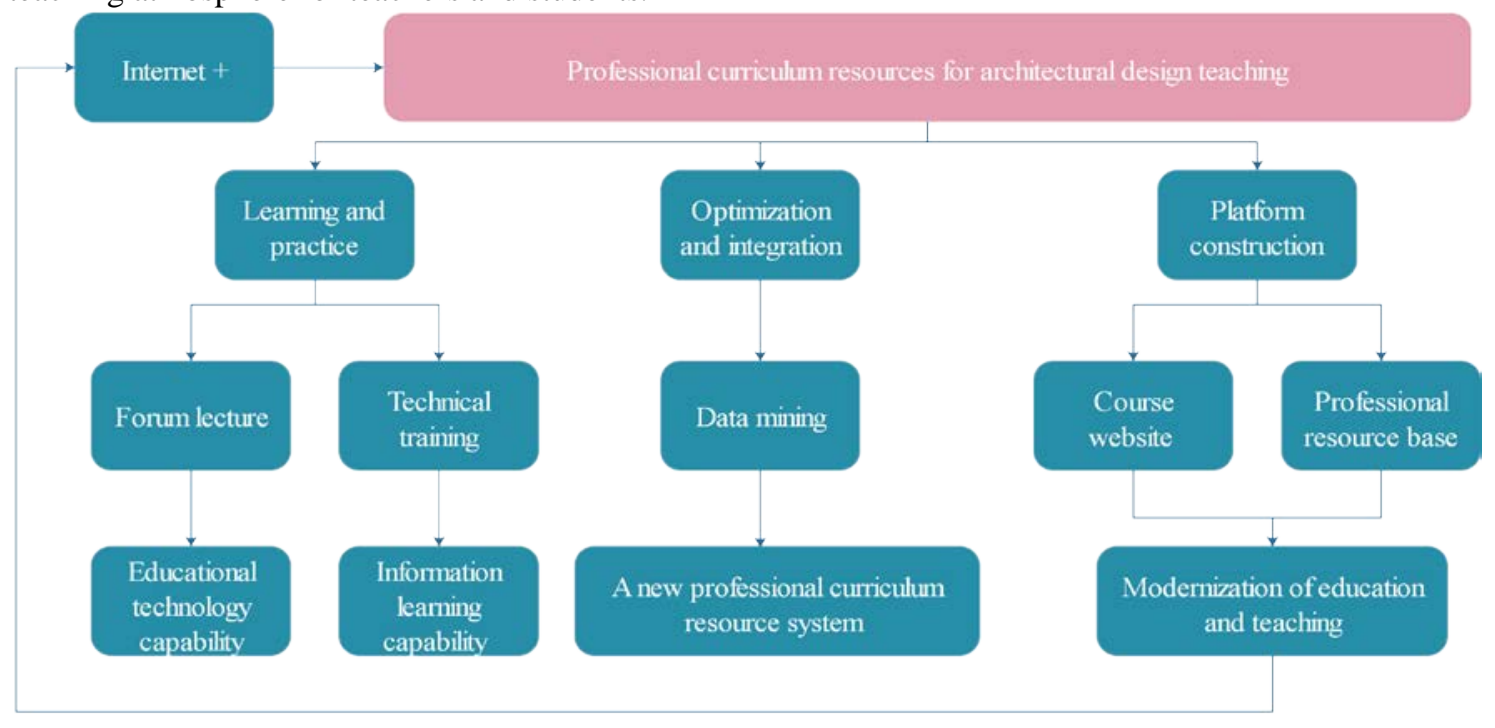

Fig. 1. The optimization and integration of curriculum resources

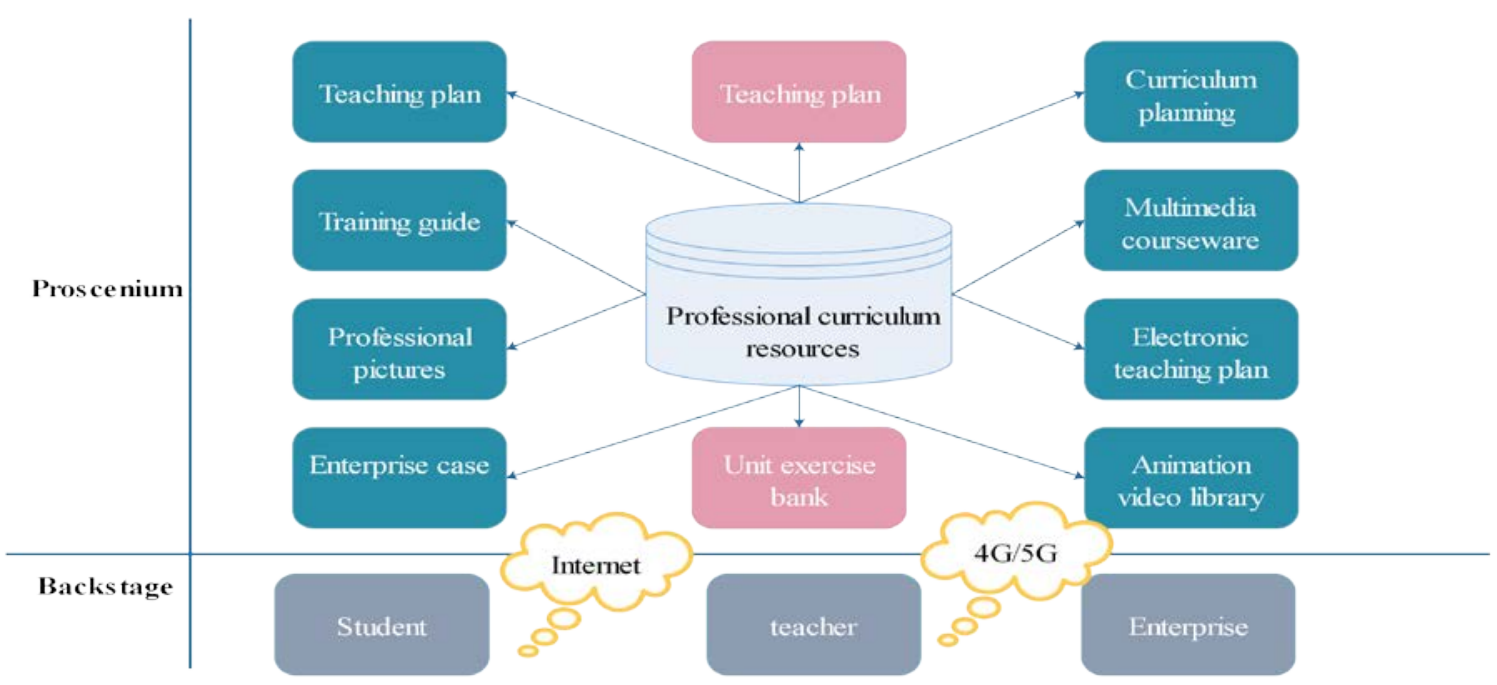

Fig. 2. The content and framework of professional resource database 


\section{Making implementation plans}

Learning and research. The training for "Internet + " and other new generation of educational information theory and technology should be strengthened. At the same time, the professional investigation is carried out for the construction enterprises. The training goal of architectural design talents, the distribution of employment posts and the professional skill standard of graduates are analyzed. The expert demonstration is hired to excavate the entry point of the integration between "Internet + " and curriculum resources, and the overall scheme of optimizing and integrating the curriculum resources for architectural engineering specialty is designed.

Integration and optimization. Based on the advantages and characteristics in the new generation of information network "Internet +", the free, democratic, loose and harmonious atmosphere of teaching and learning between teachers and students is embodied. Combined with the syllabus, enterprise cases, vocational post training and qualification examination outline, etc., the integration and optimization of the main course resources, such as "architectural drawing and CAD", "architectural mechanics", "engineering management", "building construction organization", "building construction technology", "building construction structure", "engineering survey", "building structure" and "building engineering measurement and valuation", are completed. The teaching method and design under the modern information network is innovated.

Platform construction. Based on the "Internet", the relevant knowledge resources of main courses in construction engineering, such as syllabus, electronic courseware, test question bank, review navigation, teaching video, enterprise case, etc., are reasonably designed. the online question answering and questioning links are set up, which is conductive to teaching interaction and realizing the network modernization of architectural design education and teaching.

Popularization and application. It is necessary to open the relevant resource base and course website, and promote the use to colleges, schools and society level by level. The opinions and suggestions of teachers, students and enterprises are collected to further analyze the application effect and gradually improve.

\section{Selecting working methods}

Taking advantage of "Internet +", the new method of optimizing and integrating construction engineering courses in modern information network environment are studied. Taking "Internet $+"$ as the carrier, various forms of information technology are adopted to collect and develop course teaching resources, optimize course structure and integrate resource websites, so as to offer rich and convenient learning resources and approaches for learners.
Creating a learning environment of "Internet +" and cultivating a comprehensive information literacy of talents. In the "Internet + " environment, learners can access documents, data or video resources anytime and anywhere by using various mobile terminals according to their own learning needs. Online and offline, anytime and anywhere can truly learned through synchronous or asynchronous communication, so as to realize classified and layered teaching. Promoting the similar majors reform of teaching mode and teaching method, the training quality of construction professionals and the social service ability of industry enterprises can further be improved.

\section{SUMMARY}

The learning and development of college students are faced with many opportunities and challenges in the "Internet +" background. To a large extent, it is conducive to the reform of the teaching mode in colleges' architectural design. However, the Internet is a double-edged sword. Architectural design teachers should fully realize the convenience brought by the Internet and its own advantages, guide students to use the Internet correctly, and make the Internet become their own learning power. Accelerating the application of Internet technology in the colleges' architectural design teaching, the traditional teaching mode can be fundamentally changed, and the innovation ability and comprehensive ability of students majoring in architectural design can be promoted.

\section{REFERENCES}

[1] H.B. Zhu, W.Y. Dai, and J. Li. "Reform and innovation of experiments teaching in engineering hydrodynamics." Journal of Ningbo University (2008).

[2] S.J. Hao, and H. Yang. "Discussion on Teaching Reform of AutoCAD Courses in Architectural Engineering Specialty Based on the Cultivation of Applied Innovative Ability." International Conference on Arts 2016.

[3] W. Ying. "The Research of the Teaching Mode Based on the Concept of CDIO Architectural Design." Applied Mechanics and Materials 584-586(2014):2753-2756.

[4] Jiang Wang. "The Establishment of the Innovative and Practical Teaching Mode for Architecture Majors with the Help of "Schools-Enterprises-Governments-Research Institutions"." Journal of Landscape Research 11.02(2019):111-113.

[5] Randolph, Cherilyn, and R. Main. "Exploring the Power and Politics of a PeopleSoft Implementation." Chicago (2005).

[6] Tomes Nancy. "Architecture in the Family Way: Doctors, Houses, and Women, 1870-1900 (review)." Bulletin of the History of Medicine 72.2(1998):338-339.

[7] S., Zheng, A. Burns, and L.S. Indrusiak. "Schedulability Analysis for Real Time On-Chip Communication with Wormhole Switching." Innovations in Embedded and Real-Time Systems Engineering for Communication (2010).

[8] Zhenhua, G., et al. "Reform and innovation on mechanics teaching of civil engineering specialty in Independent colleges." Journal of Architectural Education in Institutions of Higher Learning (2015). 